\title{
Is Curfew Effective in Limiting SARS-CoV-2 Progression? An Evaluation in France Based on Epidemiokinetic Analyses
}

\author{
Bruno Mégarbane, $M D, P h D^{1,2}$ (D) Fanchon Bourasset, PharmD, $P h D^{3}$, and \\ Jean-Michel Scherrmann, PharmD, PhD 2,4
}

'Department of Medical and Toxicological Critical Care, Lariboisière Hospital, Federation of Toxicology, APHP, Paris, France; ${ }^{2}$ University of Paris, INSERM UMRS-1 144, Paris, France; ${ }^{3}$ Laboratory of Integrative Research in Neurosciences and Cognitive Psychology, Bourgogne Franche-Comté University, Besancon, France; ${ }^{4}$ Laboratory of Pharmacokinetics, Faculty of Pharmacy, University of Paris, Paris, France.

BACKGROUND: Since late summer 2020, the French authorities implemented a curfew/lightened lockdownalternating strategy instead of strict lockdown, to improve acceptability and limit socioeconomic consequences. However, data on curfew-related efficacy to control the epidemic are scarce.

OBJECTIVE: To investigate the effects on COVID-19 spread in France of curfew combined to local and/or nationwide restrictions from late summer 2020 to midFebruary 2021.

DESIGN: We conducted a comparative evaluation using a susceptible-infected-recovered (SIR)-based model completed with epidemiokinetic tools.

MAIN MEASURES: We analyzed the time-course of epidemic progression rate under curfew in French Guyana and five metropolitan regions where additional restrictions were implemented at different times. Using linear regressions of the decay/increase rates in daily contaminations, we calculated the epidemic regression half-lives $\left(t_{1 / 2 \beta}\right)$ for each identified period.

KEY RESULTS: In French Guyana, two decay periods with rapid regression $\left(\mathrm{t}_{1 / 2 \beta}\right.$ of $\sim 10$ days) were observed under curfew, with slowing $\left(\mathrm{t}_{1 / 2 \beta}\right.$ of $\sim 43$ days) when curfew was lightened. During the 2 -week pre-lockdown curfew (2020/10/17-2020/11/02) in Provence-Alpes-Côted'Azur, Auvergne-Rhône-Alpes, and Ile-de-France, the epidemic progression was unchanged. During the postlockdown curfew (2020/12/15-2020/02/14), the epidemic slowly regressed in Grand-Est ( $\mathrm{t}_{1 / 2 \beta}$ of $\sim 37$ days), whereas its progression rate plateaued in AuvergneRhône-Alpes and increased immediately in ProvenceAlpes-Côte-d'Azur, Ile-de-France, and Nouvelle-Aquitaine, whatever the curfew starting time was 106:00 or 08:00 pm). Interestingly, a delayed slow decay (17 days $<\mathrm{t}_{1 / 2 \beta}<64$ days) occurred under curfew in all regions except Ile-de-France.

CONCLUSIONS: Curfew allowed the temporary control of SARS-CoV-2 epidemic, however variably in the French regions, without preventing lockdown necessity. To accelerate the epidemic regression such as observed in French Guyana, curfew should be implemented timely with additional restrictions.

Bruno Mégarbane and Fanchon Bourasset contributed equally to this work.

Received April 18, 2021

Accepted May 24, 2021

Published online June 15, 2021
KEY WORDS: COVID-19; curfew; epidemic; lockdown; modeling; SARSCoV-2.

J Gen Intern Med 36(9):2731-8

DOI: $10.1007 / \mathrm{s} 11606-021-06953-9$

(C) Society of General Internal Medicine 2021

\section{INTRODUCTION}

The world has been with the SARS-CoV-2 pandemic for more than 1 year. It has resulted in $\sim 140$ million infections and $\sim 3$ million fatalities. In Europe, a second wave was deadlier than the first one, ${ }^{1}$ forcing reluctant governments back to restrictions despite the dire economic and social consequences. In contrast with the March-April 2020 wave, during the second wave, restrictions and timings were not homogeneous across Europe with strategies variably including stay-at-home orders, workplace restrictions, school and venue closures, decreases in daily public mobility in addition to social distancing, handwashing, and facemask use.

The French government allowed regional control of restrictions. Different criteria were used including the number of daily new cases, the number of daily hospital and intensive care unit (ICU) admissions, and the percentage of ICU beds occupied. Monitoring of SARS-CoV-2 in wastewater was used when possible. ${ }^{2}$ Health authorities were concerned that restrictions might result in deleterious economic, social, and psychological effects. Initially, a curfew limited to the territories where the epidemic was the most threatening was implemented on 17 October, followed by a nationwide lockdown on 02 November 2020. Curfew was initially $10: 00 \mathrm{pm}$ to 5:00am and then extended to $8: 00 \mathrm{pm}$ to $6: 00 \mathrm{am}$. Bars and restaurants were closed while shops and schools were maintained open and teleworking and distance learning encouraged. The nationwide lockdown 15 days later closed "nonessential" shops such as hairdressers or bookstores. Shops reopened on 28 November and the lockdown ended on 15 December 2020 followed by a nationwide curfew. The effectiveness of curfew to control the epidemic was questioned.

Therefore, we designed this study to quantify the impact of curfew and other local and/or nationwide measures on the epidemic in comparison to the effects obtained with strict lockdown. Three situations where curfew was experienced in 
France were compared: 1) French Guyana, an overseas territory located in Latin America in the Amazonian forest; 2) the pre-lockdown curfew possibly combining additional local measures applied in a limited number of departments/large cities; and 3) the post-lockdown nationwide curfew.

\section{METHODS}

\section{Study Design}

In addition to French Guyana, we selected five regions, i.e., Ile-de-France (IDF), Provence-Alpes-Côte-d'Azur (PACA), Nouvelle-Aquitaine (NA), Auvergne-Rhône-Alpes (ARA), and Grand-Est (GE), and five departments, i.e., two located in PACA (Bouches-du-Rhone and Alpes-Maritimes), two located in IDF (Paris and Yvelines), and one located in NA (Gironde), based on the measures applied at variable timings in relation to the curfew.

French Guyana. Policymakers chose curfew rather than strict lockdown. The curfew began on May 5, 2020. Initially, the curfew was from 11:00pm to 05:00am every day except in Saint-Georges on the Brazilian border, where a complete lockdown was maintained. On June 10, it was extended from 09:00pm to 05:00am during weekdays and for the entire day on Sundays; on June 18, it ran 07:00pm during weekdays and 03:00pm on Saturday and during weekends to 05:00am; on June 25, it covered 05:00pm during weekdays and 01:00pm on Saturday during weekends to 05:00am. The curfew was lightened progressively by the different counties from the end of August 2020. On January 23, 2021, the curfew was again tightened, from 09:00pm to 05:00am during weekdays and the whole weekend. Terrestrial borders were closed.

Metropolitan France. Two curfews and one lockdown occurred. The first curfew began on October 17, 2020, from 09:00pm to 06:00am in certain departments, $\sim 15$ days before the nationwide lockdown (November 2 to December 15, 2020). A second curfew was established from 08:00pm to 06:00am, nationally, after the lockdown period. Besides the curfew and lockdown, other distancing measures were locally applied in PACA and NA, earlier at the end of August 2020. Hence, several cities in NA required face masking in public areas since August 2020 such as in Bordeaux center. Bars and restaurants had been closed in NA and parties were not allowed since the beginning of September 2020. In PACA, bars and restaurants had been closed from 11:00pm to 6:00am since 2020/08/26 and face masking was required in Nice and Marseille centers for everyone older than 11. At the end of September 2020, health authorities classified Bouches-du-Rhône and Gironde as maximal alert and reinforced alert areas, respectively. By contrast, no local measures to prevent the epidemic spread were undertaken in IDF, ARA, and GE during this period. However, on October 17, IDF was put on curfew until the nationwide lockdown started. There was no curfew in GE before the national lockdown. Finally, we chose ARA as an intermediate region with three departments (Rhône, Isère, and Loire) classified as reinforced alert areas on September 23 and three cities (Grenoble, Saint-Etienne, Lyon) put under curfew on October 17, 2020.

\section{Analysis Tools}

We used epidemiokinetic tools as previously described. ${ }^{3}$ Briefly, this approach is based on a simpler model with fewer parameters than the traditional compartmental susceptible-infectedrecovered (SIR) and other derived more stochastic models. Our closed three-compartmental model considers an input function (I) representing the epidemic progression and an output function representing its regression. We measure the rate at which the epidemic progresses rather than the extent of its progression. We previously showed that estimating progression and regression rates of the epidemic in real time using simple linear regressions of the rate decay in the "susceptible" compartment allowed calculating epidemic half-lives, i.e., the time necessary to alter the epidemic progression rate by $50 \%$. We estimated that at least eight half-lives were necessary to observe the complete regression of the epidemic in lockdown conditions. ${ }^{3}$ Here, we hypothesized that the efficacy of restriction measures could be evaluated simply by calculating the epidemic progression rate constants and thus the epidemic half-lives at each period.

\section{Calculations and Modeling}

For each region in France, we collected the numbers of daily new contaminations on each 7-day interval (I) from May 18, 2020, through February 2, 2021, published by Santé Publique France (https://www.santepubliquefrance.fr). As previously described, ${ }^{3}$ we calculated the epidemic progression rates as follows: $\mathrm{S}=\left(\mathrm{Ic}_{(\mathrm{n})}\right.$ $\left.-\mathrm{Ic}_{(\mathrm{n}-1)}\right) / \mathrm{Ic}_{(\mathrm{n}-1)} \times 100$, where Ic represented the cumulative infected people each week. Then, $\mathrm{S}(\mathrm{t})$ was fitted versus the midpoint time interval of each week using mono-exponential equations $\left(\mathrm{S}(\mathrm{t})=\mathrm{S}_{0} \cdot \mathrm{e}^{-\beta^{*} \mathrm{t}}\right)$. Parameters $\beta$ and $\mathrm{S}_{0}$ were estimated by the model. We calculated the epidemic progression half-lives $\left(t_{1 / 2 \beta}=\ln 2 / \beta\right)$ during each period observed in the curves. Data are expressed as estimated mean $\pm \mathrm{SD}$ (coefficient of variation, $\mathrm{CV} \%$ ). Evaluation of our models was based on the following criteria: 1) fits between observed and predicted data; 2) Akaike criteria, lowered as possible to minimize the gap between estimated and observed data; 3 ) coefficients of variation $<30 \%$; and 4) weighted residuals versus time plot that must be randomized above and below zero. Modeling was performed using Phoenix64-WinNonlin ${ }^{\mathrm{TM}}$ (Certara, USA).

\section{RESULTS}

French Guyana. The epidemic exhibited three phases, decay from June 18 to October 18, 2020, followed by increase from 
October 19, 2020, to January 10, 2021, and then decay from January 11 to February 14, 2021 (Fig. 1). Three distinct decay slopes were identified during the decreasing phases $\left(\mathrm{t}_{1 / 2 \beta \mathrm{D} 1}=10.4 \pm 0.7\right.$ days, $\mathrm{t}_{1 / 2 \beta \mathrm{D} 2}=42.9 \pm 5.3$ days, and $\mathrm{t}_{1 / 2 \beta \mathrm{D} 3}=10.6 \pm 1.4$ days) and one slope during the increase phase $\left(t_{1 / 2 \beta I 1}=29.1 \pm 4.1\right.$ days). Interestingly, the change in decay slope during the first phase coincided with the progressive curfew lightening.

Metropolitan France. Six to eight alternating phases were observed in the different regions (Figs. 2, 3, 4, 5, and 6). The D1-decay periods corresponded to the continuity of the decreasing phase observed during the first nationwide lockdown in France from March 16 to May 11, 2020, with $\mathrm{t}_{1 / 2 \beta \mathrm{D} 1}$ of 7.3 \pm 1.8 (NA), $8.0 \pm 0.8$ (PACA), 9.7 \pm 0.6 (GE), 9.7 \pm 2.1 (IDF), and $14.1 \pm 2.9$ days (ARA). The $\mathrm{D} 3$-decay periods with $\mathrm{t}_{1 / 2 \beta \mathrm{D} 3}$ of $8.7 \pm 0.7$ (ARA), $9.4 \pm 0.6$ (NA), $11.8 \pm 1.0$ (IDF), and 12.1 \pm 1.1 days (PACA) and the $\mathrm{D} 2$-decay period with $\mathrm{t}_{1 / 2 \beta \mathrm{D} 3}$ of 9.0 \pm 0.6 days in GE corresponded to the second nationwide lockdown.

The D2-decay periods observed in PACA and NA showed longer $\mathrm{t}_{1 / 2 \beta \mathrm{D} 2}(17.8 \pm 1.8$ and $16.0 \pm 1.1$ days, respectively) than in D1 (Figs. 2 and 3). This decay period was even not observed in GE and certain IDF departments such as Yvelines or just barely visible with prolonged $\mathrm{t}_{1 / 2 \beta \mathrm{D} 2}$ in Paris (62.3 \pm 7.1 days), the whole IDF $(39.3 \pm 2.2$ days), and ARA ( $34.9 \pm 4.4$ days) (Figs. 4 and 6).

The 15-day-long pre-lockdown curfew did not alter the epidemic progression in PACA and ARA (I2-increasing phases; Figs. 2 and 6) but plateaued in IDF (Fig. 4), though insufficiently to avoid a lockdown. The post-lockdown curfew allowed a slow decline in the epidemic progression rate in GE $\left(\mathrm{t}_{1 / 2 \beta}=36.5 \pm 5.8\right.$ days) with a plateau only in ARA (Fig. 6), while it did not avoid an immediate increase in PACA (I3), IDF (I2), and NA (I3) (Figs. 2, 3, and 4). A final slow decay period was observed under curfew in NA (D4), PACA (D4), and ARA (D4) but not in IDF (Figs. 2, 3, 4, 5, and 6). Of note, the early curfew from 08:00 to $06: 00 \mathrm{pm}$ did not affect the epidemic progression.

\section{DISCUSSION}

Our findings support that curfew application was effective in altering the epidemic spread in French Guyana, probably due to its geography, population characteristics, and additional measures that limited social interactions. In contrast, curfew produced relatively limited benefit in metropolitan France, with variable effects that highly depended on the nature and timing of the additional combined restriction measures, often decided at a local level.

Non-pharmaceutical interventions are the most important strategies applied to prevent SARS-CoV-2 spread in the community. Almost all governments instituted social restrictions despite dramatic socioeconomic disruption. Studies confirmed containment-related benefits on SARS-CoV-2 spread especially with early implemented and more restrictive lockdown. ${ }^{3,4}$ A series of control measures in China allowed effectively controlling the epidemic in early April 2020 with very few new cases occasionally reported. ${ }^{5}$ Korea was one out of the rare countries never under lockdown to succeed controlling the first wave to a manageable level, due to public compliance in following personal hygiene principles and social distancing. ${ }^{6}$

In French Guyana, our findings suggest that the territorial strategy mainly based on curfew with social distancing measures, stricter than those applied in metropolitan France such as school (during the first curfew period) and border closures (during the two curfew periods), was efficient to control the epidemic spread. The two phases of reinforced curfews resulted in almost similar impact as if strict lockdown was applied ${ }^{3}$; however, curfew impact was markedly reduced when restrictions started to be lightened by the different counties. While our analyses were unable to identify the specific curfewrelated benefits, the observed limitation in epidemic spread in French Guyana was clearly attributed to its combination with other social interaction-limiting measures, as previously suggested. ${ }^{7}$

In metropolitan France, the first nationwide lockdown successfully reduced the burden on the medical care system in IDF and GE regions and prevented the epidemic spread to the other regions. ${ }^{8}$ However, with the summer-ending epidemic progression and continuous increase in SARS-CoV-2attributed deaths, policymakers struggled. Wishing to avoid a new lockdown, they considered more economically compatible and socially acceptable restrictions. A nationwide curfew was preferred. However, our data show that curfew's ability to control the epidemic was limited, highly depending on its timing and conditions. In PACA and ARA, the first curfew failed to reduce the epidemic progression (Figs. 2 and 6). The post-lockdown curfew variably affected the epidemic progression, whatever its starting time was $(06: 00 \mathrm{pm}$ or $08: 00 \mathrm{pm})$. Hence, the spread plateaued in ARA (Fig. 6) and immediately increased in PACA, NA, and IDF (Figs. 2, 3, and 4) while immediately decreased in GE (Fig. 5). Interestingly, a delayed spread regression was observed in NA, PACA, and ARA but not in IDF, starting at the time of large shopping center closure $\left(>20,000 \mathrm{~m}^{2}\right)$ in combination with curfew measures. Our data are in agreement with those showing that among all nonpharmaceutical interventions, shop closing is one of the most effective measure to control the epidemic spread. ${ }^{9}$ However, closure of only large shopping centers in France was not enough to slow the spread as obtained with strict lockdown. Moreover, although the overall restriction policy was able to alter the contamination progression and limit pressure on health services, earlier in the metropolitan areas where first implemented, ${ }^{10}$ its efficacy in limiting SARS-CoV-2attributed mortality over the winter period is questionable. 
(A)

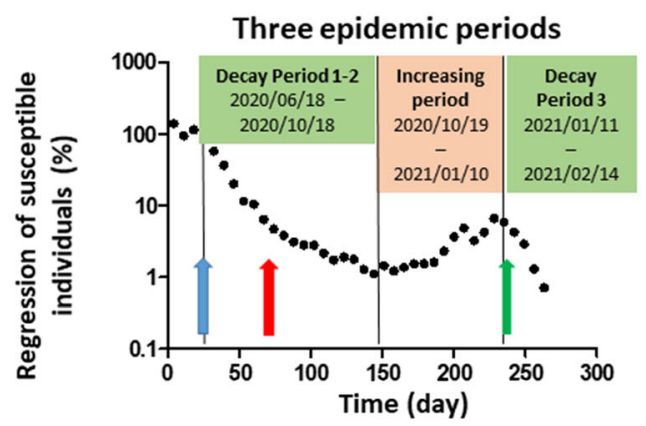

(B)

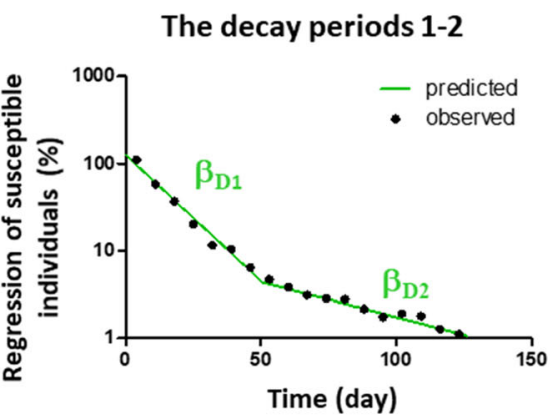

The decay period 3

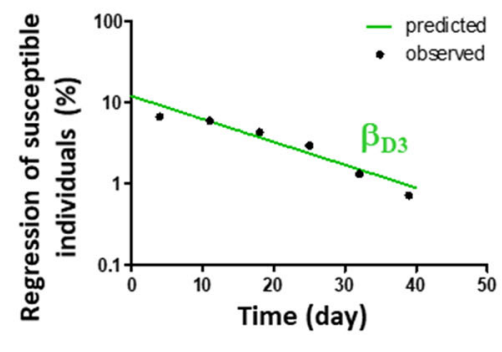

(C)

The increasing period 1
(D)

\begin{tabular}{|c|c|c|c|c|}
\cline { 2 - 5 } \multicolumn{1}{c|}{} & $\begin{array}{c}\text { Decay period } \\
\text { Curfew and social } \\
\text { distancing measures } \\
\beta_{\mathrm{D} 1}\end{array}$ & $\begin{array}{c}\text { Decay period } \\
\text { Curfew and social } \\
\text { distancing measures } \\
\beta_{\mathrm{D} 2}\end{array}$ & $\begin{array}{c}\text { Decay period } \\
\text { Increasing period } \\
\beta_{\mathrm{I} 1}\end{array}$ & $\begin{array}{c}\text { Curfew and social } \\
\text { distancing measures } \\
\beta_{\mathrm{D} 3}\end{array}$ \\
\hline$\beta\left(\right.$ day $\left.^{-1}\right)$ & $0.067 \pm 0.004(6.3)$ & $0.019 \pm 0.001(6.9)$ & $\begin{array}{c}0.024 \pm 0.003 \\
(14.1)\end{array}$ & $0.065 \pm 0.008(12.8)$ \\
\hline $\mathrm{t}_{1 / 2}($ day) & $10.4 \pm 0.7(6.3)$ & $42.9 \pm 5.3(6.9)$ & $29.1 \pm 4.1(14.1)$ & $10.6 \pm 1.4(12.8)$ \\
\hline Correlation coefficient $\left(\mathrm{r}^{2}\right)$ & 0.99 & 0.98 & 0.87 & 0.94 \\
\hline Akaike criteria & -10.8 & -23.8 & -6.1 & -4.6 \\
\hline
\end{tabular}

Fig. 1 Regression of susceptible individuals $(S(t), \%)$ in French Guyana from May 18, 2020, to February 14, 2021, presented in a semilogarithmic scale. A Total observed data could be divided into three decay (D, green) and one increasing periods (I, red). B Determination of three distinct decreasing slopes named $\beta_{\mathrm{D} 1}, \beta_{\mathrm{D} 2}$, and $\beta_{\mathrm{D} 3}$ for the decay periods. C Determination of the increasing slope named $\beta_{\mathrm{I} 1}$ for the increasing period. D Calculation of the different epidemic half-lives (expressed as estimated mean value \pm SD (CV\%)). The curfew, setup on 2020/05/11, persisted almost permanently with a first reinforcement on June 18, 2020 (blue arrow), a progressive lightening from the end of August 2020 (red arrow), and a new reinforcement on 2021/01/23 (green arrow).

(A)

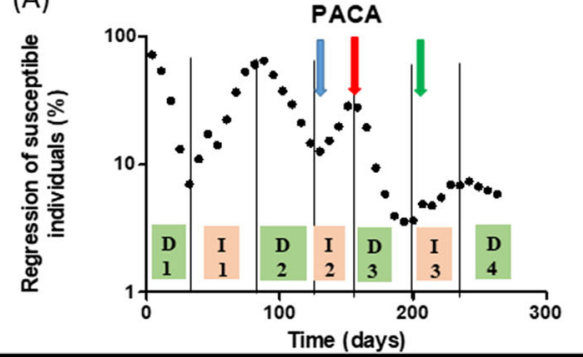

(B)

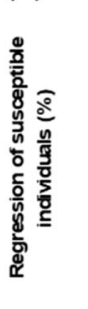

Bouches-du-Rhône (13)

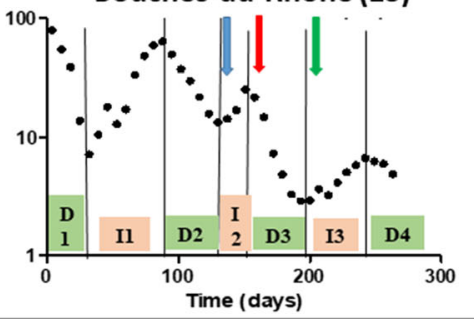

(C)

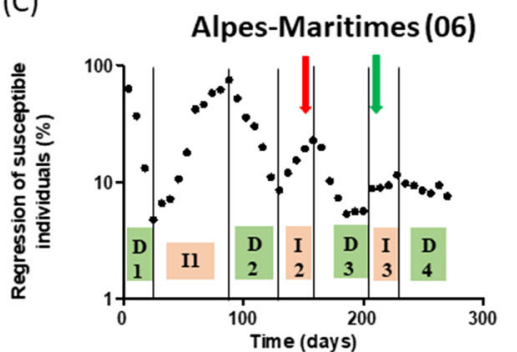

\footnotetext{
Dl Decay period 1: 2020/05/18 -2020/06/22 (PACA, 13) or 2020/06/15 (06)

Il Increasing period 1: 2020/06/23 (PACA, 13) or 2020/06/16 (06) - 2020/08/19

I2 Increasing period 2: 2020/10/05 - 2020/11/01 (PACA, 13) or 2020/11/08 (06)

D3 Decay period 3: 2020/11/02 (PACA, 13) or 2020/11/09 (06) - 2020/12/06

I3 Increasing period 2: 2020/12/07 - 2021/01/13

D4 Decay period 4: 2021/01/14 - 2021/02/14
}

\begin{tabular}{|c|c|c|c|c|c|c|c|c|}
\hline \multicolumn{2}{|l|}{ (D) } & $\begin{array}{c}\text { Decay period } 1 \\
\beta_{D 1}\end{array}$ & $\begin{array}{c}\text { Increasing period } 1 \\
\beta_{\mathrm{I} 1}\end{array}$ & $\begin{array}{c}\text { Decay period } 2 \\
\beta_{\mathrm{D} 2}\end{array}$ & $\begin{array}{c}\text { Increasing period } 2 \\
\beta_{12}\end{array}$ & $\begin{array}{c}\text { Decay period } 3 \\
\beta_{03}\end{array}$ & $\begin{array}{c}\text { Increasing period } 3 \\
\beta_{13}\end{array}$ & $\begin{array}{c}\text { Decay period } 4 \\
\beta_{04}\end{array}$ \\
\hline \multirow{3}{*}{ PACA region } & $\mathrm{T}_{1 / 2}(\mathrm{day})$ & $8.0 \pm 0.8(9.7)$ & $16.1 \pm 1.4(8.5)$ & $17.2 \pm 0.55(3.2)$ & $17.8 \pm 1.8(10.1)$ & $12.1 \pm 1.1(9.5)$ & $42.3 \pm 6.0(14.1)$ & $64.4 \pm 3.6(5.6)$ \\
\hline & Correlation coefficient $\left(r^{2}\right)$ & 0.97 & 0.98 & 0.99 & 0.99 & 0.95 & 0.95 & 0.99 \\
\hline & Akaike criteria & -7.4 & -10.5 & -27 & -15.6 & -7.1 & -19.2 & -30.5 \\
\hline \multirow{3}{*}{ Bouches de Rhône (13) } & $\mathrm{T}_{1 / 2}$ (day) & $7.9 \pm 1.0(12.9)$ & $17.0 \pm 1.7(9.7)$ & $18.1 \pm 0.5(2.7)$ & $22.9 \pm 5.8(25.1)$ & $11.5 \pm 1.1(9.5)$ & $35.8 \pm 4.2(11.7)$ & $\begin{array}{c}48.9 \pm 12.4 \\
(25.4)\end{array}$ \\
\hline & Correlation coefficient $\left(r^{2}\right)$ & 0.97 & 0.97 & 0.99 & 0.95 & 0.99 & 0.98 & 0.94 \\
\hline & Akaike criteria & -4.3 & -6.3 & -30.6 & -10.3 & -9.1 & -19.4 & -16.2 \\
\hline \multirow{3}{*}{ Alpes-Maritime (06) } & $\mathrm{T}_{1 / 2}$ (days) & $5.5 \pm 0.5(9.8)$ & $14.4 \pm 1.6(11.2)$ & $13.4 \pm 0.7(5.5)$ & $19.8 \pm 1.4(7.3)$ & $12.4 \pm 1.3(10.6)$ & $32.8 \pm 9.2(27.9)$ & $\begin{array}{c}91.5 \pm 29.6 \\
(32.3)\end{array}$ \\
\hline & Correlation coefficient $\left(r^{2}\right)$ & 0.98 & 0.93 & 0.99 & 0.99 & 0.97 & 0.92 & 0.83 \\
\hline & Akaike criteria & -7.6 & -0.7 & -16.3 & -19.3 & -10.8 & -10.9 & -18.3 \\
\hline
\end{tabular}

Fig. 2 Regression of susceptible individuals $(\mathrm{S}(\mathrm{t}), \%)$ in A Provence-Alpes-Côte-d'Azur (PACA) region and B Bouches-du-Rhône (13) and C Alpes-Maritimes (06) departments from May 18, 2020, to February 14, 2021, presented in a semi-logarithmic scale. A-C Total observed data divided into seven distinct periods: four decay (D, green) and three increasing periods (I, red). D Calculation of the different epidemic half-lives (expressed as estimated mean value \pm SD $(C V \%)$ ). The implementation timings of restriction measures are indicated on the graphs as follows: pre-lockdown curfew (blue arrow), lockdown (red arrow), and post-lockdown curfew (green arrow). 


\section{Nouvelle-Aquitaine}

(A)

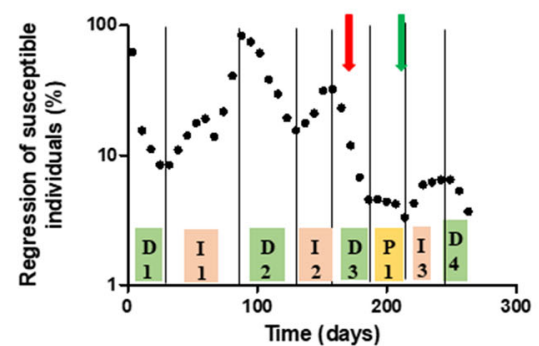

(B)

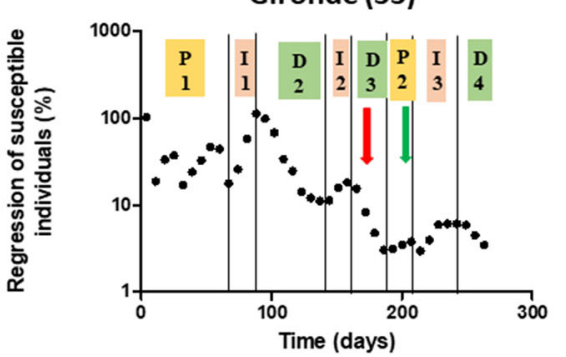

\begin{tabular}{|c|c|c|c|c|c|c|c|}
\hline Dl & Decay period 1: 2020/05/18 - 2020/06/21 & D3 & $\begin{array}{c}\text { Decay period 3: } 2020 / 10 / 26 \text { - } \\
2020 / 11 / 29\end{array}$ & Pl & Plateau: $2020 / 05 / 18-2020 / 08 / 02$ & D3 & Decay period $3: 2020 / 10 / 26-2020 / 11 / 29$ \\
\hline Il & Increasing period $1: 2020 / 6 / 22-2020 / 08 / 23$ & P1 & Plateau : $2020 / 11 / 30-2021 / 12 / 20$ & Il & Increasing period 1: 2020/08/03-2020/08/23 & P2 & Plateau: $2020 / 11 / 30-2021 / 12 / 20$ \\
\hline D2 & Decay period 2: 2020/08/24 -2020/10/04 & I3 & Increasing period $3: 2020 / 12 / 21$ - & D2 & Decay period 2: 2020/08/24 - 2020/10/04 & I3 & Increasing period 3: 2020/12/21 -2021/01/17 \\
\hline I2 & Increasing period 2: 2020/10/05 - 2020/10/25 & D4 & $\begin{array}{c}2021 / 01 / 24 \\
\text { Decay period 4: } 2021 / 01 / 25 \text { - } \\
2021 / 02 / 14\end{array}$ & I2 & Increasing period 2: $2020 / 10 / 05-2020 / 10 / 25$ & D4 & Decay period 4: 2021/01/18 - 2021/02/14 \\
\hline
\end{tabular}

\begin{tabular}{|c|c|c|c|c|c|c|c|c|c|c|}
\hline \multicolumn{2}{|l|}{ (C) } & Plateau 1 & $\begin{array}{c}\text { Decay period } 1 \\
\beta_{D 1}\end{array}$ & $\begin{array}{c}\text { Increasing period } 1 \\
\beta_{\mathrm{I} 1}\end{array}$ & $\begin{array}{c}\text { Decay period } 2 \\
\beta_{02}\end{array}$ & $\begin{array}{c}\text { Increasing period } 2 \\
\beta_{12}\end{array}$ & $\begin{array}{c}\text { Decay period } 3 \\
\beta_{03}\end{array}$ & Plateau 2 & $\begin{array}{c}\text { Increasing period } 3 \\
\beta_{13}\end{array}$ & $\begin{array}{c}\text { Decay period } 4 \\
\beta_{04}\end{array}$ \\
\hline \multirow{3}{*}{$\begin{array}{l}\text { Nouvelle- } \\
\text { Aquitaine } \\
\text { region }\end{array}$} & $T_{1 / 2}($ day $)$ & & $7.3 \pm 1.8(25.3)$ & $22.8 \pm 3.7(16.2)$ & $16.0 \pm 1.1(6.6)$ & $21.0 \pm 3.9(18.6)$ & $9.4 \pm 0.6(6.1)$ & n.a. & $22.9 \pm 4.7(20.4)$ & $17.1 \pm 3.1(17.6)$ \\
\hline & Correlation coefficient $\left(r^{2}\right)$ & & 0.95 & 0.87 & 0.98 & 0.97 & 0.99 & n.a. & 0.91 & 0.98 \\
\hline & \begin{tabular}{|c|} 
Akaike criteria \\
\end{tabular} & & -0.98 & -5.7 & -16.2 & -11.9 & -13.5 & n.a. & -10.4 & -11.9 \\
\hline \multirow{3}{*}{ Gironde (33) } & $T_{1 / 2}$ (day) & n.a. & & $7.6 \pm 0.7(9.4)$ & $13.0 \pm 1.0(8.0)$ & $20.2 \pm 4.8(23.8)$ & $8.9 \pm 0.4(4.8)$ & n.a. & $18.1 \pm 3.8(21.3)$ & $24.3 \pm 4.9(20.1)$ \\
\hline & Correlation coefficient $\left(r^{2}\right)$ & n.a. & & 0.99 & 0.98 & 0.97 & 0.99 & n.a. & 0.93 & 0.95 \\
\hline & \begin{tabular}{|c|} 
Akaike criteria \\
\end{tabular} & n.a. & & -9.3 & -7.9 & -11.1 & -16.0 & n.a. & -9.7 & -12.5 \\
\hline
\end{tabular}

Fig. 3 Regression of susceptible individuals $(\mathrm{S}(\mathrm{t}), \%)$ in A Nouvelle-Aquitaine (NA) region and B Gironde (33) department from May 18, 2020, to February 14, 2021, showed in a semi-logarithmic scale. A, B Total observed data divided into 8 distinct periods: four (NA) or three (33) decays (D, green), one (NA) or two (33) plateaus (P, yellow), and three increasing periods (I, red). C Calculation of the different epidemic halflives (expressed as estimated mean value \pm SD $(\mathrm{CV} \%)$ ). The implementation timings of restriction measures are indicated on the graphs as follows: lockdown (red arrow) and post-lockdown curfew (green arrow).

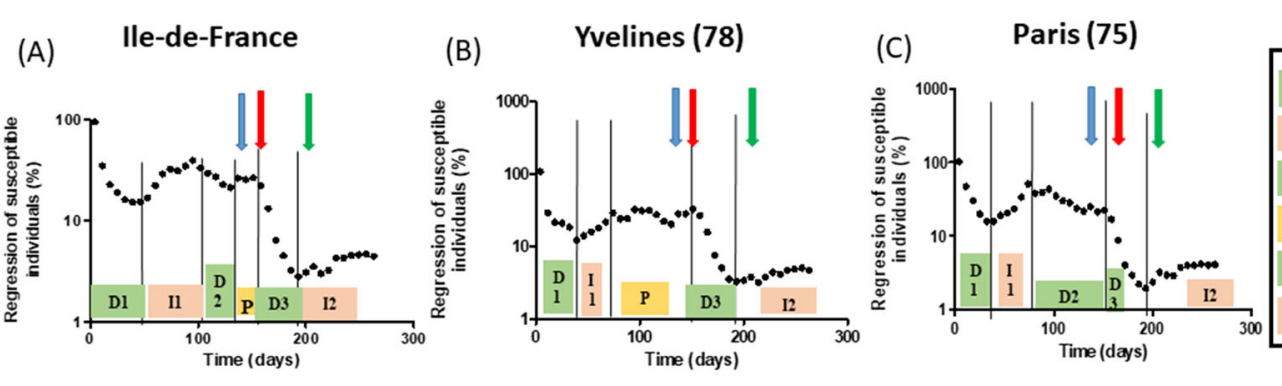

Ile-de-France

(D)

\begin{tabular}{|c|c|c|c|c|c|c|c|}
\hline \multicolumn{2}{|l|}{ D) } & $\begin{array}{c}\text { Decay period } 1 \\
\beta_{01}\end{array}$ & $\begin{array}{c}\text { Increasing period } 1 \\
\beta_{\mathrm{I} 1}\end{array}$ & $\begin{array}{c}\text { Decay period } 2 \\
\beta_{\mathrm{D} 2}\end{array}$ & Plateau & $\begin{array}{c}\text { Decay period } 3 \\
\beta_{03}\end{array}$ & $\begin{array}{c}\text { Increasing period } 2 \\
\beta_{13}\end{array}$ \\
\hline \multirow{3}{*}{$\begin{array}{l}\text { lle-de- } \\
\text { France } \\
\text { region }\end{array}$} & $\mathrm{T}_{1 / 2}$ (day) & $9.7 \pm 2.1(22.0)$ & $36.9 \pm 4.9(13.4)$ & $39.3 \pm 2.2(5.7)$ & n.a. & $11.8 \pm 1.0(8.2)$ & $88.5 \pm 13.7$ (15.5) \\
\hline & $\begin{array}{c}\text { Correlation } \\
\text { coefficient }\left(r^{2}\right)\end{array}$ & 0.95 & 0.95 & 0.99 & n.a. & 0.98 & 0.89 \\
\hline & Akaike criteria & 15.7 & -16.4 & -30 & n.a. & -8.8 & -25.1 \\
\hline \multirow{3}{*}{ Paris (75) } & $\mathrm{T}_{1 / 2}$ (day) & $10.6 \pm 1.5(15.5)$ & $21.4 \pm 3.1(14.4)$ & $62.3 \pm 7.1(11.4)$ & & $11.1 \pm 1.1(9.8)$ & $86.2 \pm 16.4(19.0)$ \\
\hline & $\begin{array}{c}\text { Correlation } \\
\text { coefficient }\left(r^{2}\right)\end{array}$ & 0.97 & 0.96 & 0.94 & & 0.99 & 0.87 \\
\hline & Akaike criteria & 16.6 & -11.6 & -22.1 & & -5.5 & -9.3 \\
\hline \multirow{3}{*}{$\begin{array}{l}\text { Yvelines } \\
\text { (78) }\end{array}$} & $\mathrm{T}_{1 / 2}$ (day) & $10.0 \pm 2.6(25.6)$ & $29.2 \pm 2.7(9.2)$ & & n.a. & $10.0 \pm 0.7(6.9)$ & $86.6 \pm 13.6(15.7)$ \\
\hline & $\begin{array}{c}\text { Correlation } \\
\text { coefficient }\left(r^{2}\right)\end{array}$ & 0.90 & 0.98 & & n.a. & 0.98 & 0.89 \\
\hline & Akaike criteria & 23.5 & -20.6 & & n.a. & -11.2 & -25.8 \\
\hline
\end{tabular}

\begin{tabular}{|c|l|}
\hline D1 & Decay period 1: 2020/05/18 $-2020 / 07 / 05$ \\
\hline I1 & Increasing period 1: 2020/07/06 -2020/08/19 \\
\hline D2 & Decay period 2: 2020/08/20 -2020/10/04 \\
\hline P & Plateau : 2020/10/05 $-2020 / 11 / 01$ \\
\hline D3 & Decay period 3: 2020/11/02 - 2020/12/06 \\
\hline I2 & Increasing period 2: 2020/12/07 -2021/02/14 \\
\hline Yvelines (78) \\
\hline
\end{tabular}

Yvelines (78)

\begin{tabular}{|c|l|}
\hline D1 & Decay period 1: 2020/05/18 $-2020 / 06 / 28$ \\
\hline Il & Increasing period 1:2020/06/29 - 2020/08/09 \\
\hline P1 & Decay period 2: 2020/08/10 - 2020/10/25 \\
\cline { 1 - 1 } D3 & Decay period 3: 2020/10/26 - 2020/12/06 \\
\cline { 1 - 1 } I2 & Increasing period 2:2020/12/07 - 2021/02/14 \\
\hline
\end{tabular}

Paris (75)

\begin{tabular}{|c|l|}
\hline D1 & Decay period 1: 2020:05/18 $-2020 / 06 / 28$ \\
\hline I1 & Increasing period 1: 2020/06/29 -2020/08/09 \\
\hline D2 & Decay period 2: 2020/08/10 - 2020/10/25 \\
\hline D3 & Decay period 3: 2020/10/26 - 2020/12/06 \\
\hline I2 & Increasing period 2: 2020/12/07 - 2021/02/14 \\
\hline
\end{tabular}

Fig. 4 Regression of susceptible individuals (S(t), \%) in A Ile-de-France (IDF) region and B in Yvelines (78) and C Paris (75), two IDF departments, from May 18, 2020, to February 14, 2021, showed in a semi-logarithmic scale. A-C Total observed data divided into five or six distinct periods: two or three decays (D, green), none or one plateau (P, yellow). and two increasing periods (I, red). D Calculation of the different epidemic half-lives (expressed as estimated mean value \pm SD $(\mathrm{CV} \%)$ ). The implementation timings of restriction measures are indicated on the graphs as follows: lockdown (red arrow) and post-lockdown curfew (green arrow). 

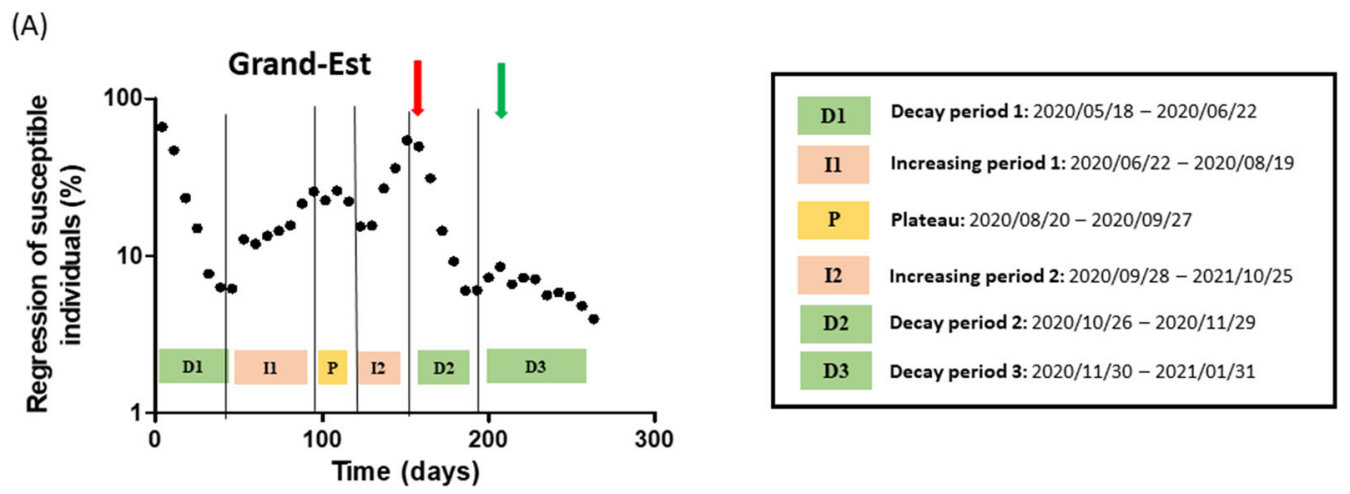

(B)

\begin{tabular}{|c|c|c|c|c|c|c|}
\cline { 2 - 7 } & $\begin{array}{c}\text { Decay period 1 } \\
\beta_{\mathrm{D} 1}\end{array}$ & $\begin{array}{c}\text { Increasing period 1 } \\
\beta_{\mathrm{I} 1}\end{array}$ & Plateau & $\begin{array}{c}\text { Increasing period 2 } \\
\beta_{\mathrm{I} 2}\end{array}$ & $\begin{array}{c}\text { Decay period 2 } \\
\beta_{\mathrm{D} 2}\end{array}$ & $\begin{array}{c}\text { Decay period 3 } \\
\beta_{\mathrm{D} 3}\end{array}$ \\
\hline $\mathrm{T}_{1 / 2}$ (day) & $9.7 \pm 0.6(6.2)$ & $21.8 \pm 4.0(18.5)$ & n.a. & $12.1 \pm 1.1(8.7)$ & $9.0 \pm 0.6(6.1)$ & $36.5 \pm 5.8(15.9)$ \\
\hline Correlation coefficient $\left(\mathrm{r}^{2}\right)$ & 0.99 & 0.96 & n.a. & 0.99 & 0.99 & 0.97 \\
\hline Akaike criteria & -12.2 & -2.8 & n.a. & -13.6 & -13.0 & -17.6 \\
\hline
\end{tabular}

Fig. 5 Regression of susceptible individuals (S(t),\%) in the Grand-Est (GE) region from May 18, 2020, to February 14, 2021, showed in a semilogarithmic scale. A Total observed data divided into six distinct periods: three decay periods (D, green), one plateau (P, yellow), and two

increasing periods (I, red). B Calculation of the different epidemic half-lives (expressed as estimated mean value \pm SD (CV\%)). The implementation timings of restriction measures are indicated on the graphs as follows: pre-lockdown curfew (blue arrow), lockdown (red arrow), and post-lockdown curfew (green arrow).

In early August, restrictions were decided locally at the regional, departmental, and/or city level including bar/ restaurant closure, student party prohibition, and face masking in the public space, explaining the epidemic decline. In the regions/departments where these measures were not applied, this spread decrease was not (such as in GE and Yvelines) or barely observed (such as in Paris, IDF, and ARA) by contrast to PACA and NA (Figs. 2, 3, 4, 5, and 6). These local measures initiated early in August, such as in the 06 and 33 departments, allowed reaching regression rates equivalent to those obtained with a strict lockdown initiated in a later stage of the epidemic, showing that anticipation of less stringent restrictions may be as efficient as lockdown to control the epidemic.
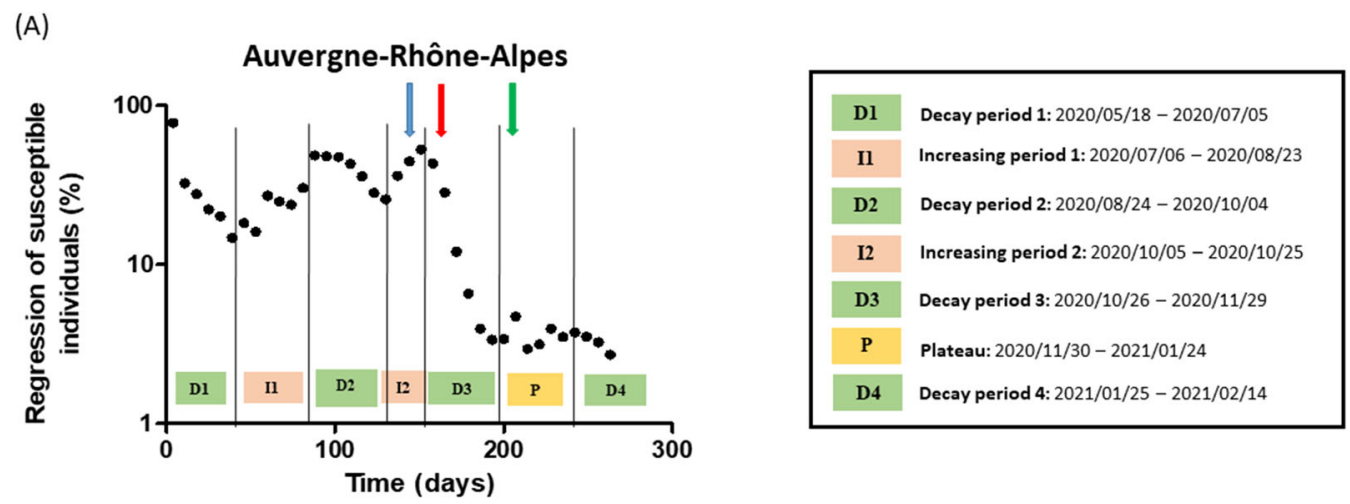

(B)

\begin{tabular}{|c|c|c|c|c|c|c|c|}
\hline & $\begin{array}{c}\text { Decay period } 1 \\
\beta_{D 1}\end{array}$ & $\begin{array}{c}\text { Increasing period } 1 \\
\beta_{\mathrm{I} 1}\end{array}$ & $\begin{array}{c}\text { Decay period } 2 \\
\beta_{\mathrm{D} 2}\end{array}$ & $\begin{array}{c}\text { Increasing period } 2 \\
\beta_{\mathrm{I} 2}\end{array}$ & $\begin{array}{c}\text { Decay period } 3 \\
\beta_{\mathrm{D} 3}\end{array}$ & Plateau & $\begin{array}{c}\text { Decay period } 4 \\
\beta_{\mathrm{D} 4}\end{array}$ \\
\hline $\mathrm{T}_{1 / 2}$ (day) & $14.1 \pm 2.9(20.2)$ & $22.8 \pm 4.1(18.0)$ & $34.9 \pm 4.4(12.6)$ & $20.5 \pm 2.5(12.0)$ & $8.7 \pm 0.7(8.2)$ & n.a & $46.2 \pm 8.5(18.5)$ \\
\hline Correlation coefficient $\left(r^{2}\right)$ & 0.92 & 0.91 & 0.96 & 0.99 & 0.96 & n.a & 0.97 \\
\hline Akaike criteria & 17.2 & -4.0 & -19.1 & -15.3 & -7.4 & n.a & -18.3 \\
\hline
\end{tabular}

Fig. 6 Regression of susceptible individuals (S(t),\%) in Auvergne-Rhône-Alpes (ARA) region from May 18, 2020, to February 14, 2021, showed in a semi-logarithmic scale. A Total observed data divided into seven distinct periods: four decay periods $(\mathrm{D}$, green), one plateau $(\mathrm{P}$, yellow), and two increasing periods (I, red). B Calculation of the different epidemic half-lives (expressed as estimated mean value \pm SD (CV\%)). The implementation timings of restriction measures are indicated on the graphs as follows: pre-lockdown curfew (blue arrow), lockdown (red arrow), and post-lockdown curfew (green arrow). 
Although lockdown outperforms less stringent restrictions in reducing cumulative deaths, ${ }^{11}$ alternatives for lockdown stringency, time, and duration have been proposed; however, their relative advantages have been only evaluated based on predictive models. The quarantine strategy weekly alternating half of the population on activity and the second half under quarantine and vice versa was shown to provide a dramatic reduction in transmission, comparable to that achieved by a population-wide lockdown, despite maintaining half of the socioeconomic continuity at $50 \%$ of its capacity. ${ }^{12}$ Since weekly alternation synchronizes with SARS-CoV-2 disease time-scale, this strategy allows isolating infected persons at the time of their peak infection.

Lockdown-release strategy is also determinant, as illustrated in France, by the dramatic and sudden stop of lockdowninduced decrease in the epidemic when non-essential shop reopened on November 28, 2020. Policymakers should be wary of lockdown-release strategies based on a thresholddependent on-off mechanism and continue lockdown until the number of new contaminations reaches a sufficiently low threshold. Time to reach this threshold can be easily estimated by our method by measuring the epidemic regression half-life, knowing that the end of the exponential process describing the epidemic regression during lockdown would be reached after 8-10 times the half-life. ${ }^{3}$ Circuit breaker lockdowns are effective to delay infection peak but not the total infection load and infection peak. ${ }^{13}$ There may be alterations to behavior with closer contact (e.g., increased shopping and socializing) days before implementation. However, despite modest reductions in $\mathrm{R}$, the significant changes to dynamics may prevent overburdening health services during the next few months. A gradual release strategy by allowing different population fractions in lockdown to re-enter the working non-quarantined population seems more effective than an "on-off" strategy of releasing everyone but re-establishing lockdown if infections become too high. ${ }^{14}$ The optimal strategy was found to be to release half the population $2-4$ weeks from the end of an initial infection peak, and then wait another 3-4 months to allow for a second peak before releasing everyone else.

To be effective, restrictions should be adapted to the timevarying estimation of the epidemic spread. ${ }^{15}$ Epidemic wave modeling uncertainties in the estimates of prevalence and simulate of super-spreader presence are concerning. ${ }^{16}$ Most countries have chosen to implement tiered restriction system based on regional infection levels. Implementation of mass testing campaign to halt the epidemic growth in France was questioned but based on a modeling study proved relevant only if the epidemic is limited by other interventions. ${ }^{17}$ Based on models, the epidemic was only shown to vanish if complete lockdown is imposed; otherwise, its presence persists in the population. ${ }^{18}$ The epidemic could be kept under control by implementing contact tracing and quarantine measures along with lockdown if imposed partially. Limited evidence supports that combination of lockdown and mass screening might result in a greater reduction of contaminations and fatalities in comparison to lockdown only. ${ }^{19}$ The exact contribution of curfew combined to mass screening has not been evaluated.

To conclude, curfew is not as effective in controlling SARS-Cov-2 epidemic spread as stricter measures including stay-at-home orders. However, combining curfews with additional restriction measures can slow the spread. The most critical issue is to initiate restrictive measures as early as possible.

Corresponding Author: Bruno Mégarbane, $M D, P h D$; Department of Medical and Toxicological Critical Care, Lariboisière Hospital, Federation of Toxicology, APHP, Paris, France (e-mail: bruno. megarbane@lrb.aphp.fr).

Author Contribution Concept and design: all three authors; acquisition, analysis, or interpretation of data: all three authors; drafting of the manuscript: Mégarbane, Bourasset; critical revision of the manuscript for important intellectual content: all three authors.

Funding The investigation, analysis, and manuscript preparation were completed as part of official duties at the university hospital.

Data Availability Dr. Mégarbane had full access to all of the data in the study and takes responsibility for data integrity and data analysis accuracy. Data are available from the corresponding author on reasonable request.

\section{Declarations:}

Conflict of Interest: The authors declare that they do not have a conflict of interest.

\section{REFERENCES}

1. Nørgaard SK, Vestergaard LS, Nielsen J, Richter L, Schmid D, Bustos N, et al. Real-Time Monitoring Shows Substantial Excess All-Cause Mortality During Second Wave of COVID-19 in Europe, October to December 2020. Euro Surveill. 2021;26:2002023. https://doi.org/10.2807/15607917.ES.2021.

2. Trottier J, Darques R, Ait Mouheb N, Partiot E, Bakhache W, Deffieu MS, Gaudin R. Post-Lockdown Detection of SARS-CoV-2 RNA in the Wastewater of Montpellier, France. One Health. 2020;10:100157. https://doi. org/10.1016/j.onehlt.2020.100157.

3. Mégarbane B, Bourasset F, Scherrmann JM. Is Lockdown Effective in Limiting SARS-CoV-2 Epidemic Progression?-a Cross-Country Comparative Evaluation Using Epidemiokinetic Tools. J Gen Intern Med. 2021;36:746-752. https://doi.org/10.1007/s11606-020-06345-5.

4. Caristia S, Ferranti M, Skrami E, Raffetti E, Pierannunzio D, Palladino R, et al. Effect of National and Local Lockdowns on the Control of COVID-19 Pandemic: a Rapid Review. Epidemiol Prev. 2020;44:60-68. https://doi. org/10.19191/EP20.5-6.S2.104.

5. Zhang B, Zhou H, Zhou F. Study on SARS-CoV-2 Transmission and the Effects of Control Measures in China. PLoS One. 2020;15:e0242649. https://doi.org/10.1371/journal.pone.0242649.

6. Kim S, Kim YJ, Peck KR, Ko Y, Lee J, Jung E. Keeping Low Reproductive Number Despite the Rebound Population Mobility in Korea, a Country Never under Lockdown during the COVID-19 Pandemic. Int J Environ Res Public Health. 2020;17:9551. https://doi.org/10.3390/ ijerph 17249551.

7. Andronico A, Tran Kiem C, Paireau J, Succo T, Bosetti P, Lefrancq N, et al. Evaluating the Impact of Curfews and Other Measures on SARS-CoV-2 Transmission in French Guiana. Nat Commun. 2021;12:1634. https:// doi.org/10.1038/s41467-021-21944-4.

8. Cauchemez S, Kiem CT, Paireau J, Rolland P, Fontanet A. Lockdown Impact on COVID-19 Epidemics in Regions Across Metropolitan France. Lancet. 2020;396:1068-1069. https://doi.org/10.1016/S0140-6736(20) 32034-1. 
9. Sharma M, Mindermann S, Rogers-Smith C, Leech G, Snodin B, et al. Understanding the Effectiveness of Government Interventions in Europe's Second Wave of COVID-19. MedRxiv. 2021. https://doi.org/ 10.1101/2021.03.25.21254330.

10. Spaccaferri G, Larrieu S, Pouey J, Calba C, Benet T, Sommen C, et al. Early Assessment of the Impact of Mitigation Measures to Control COVID-19 in 22 French Metropolitan Areas, October to November 2020. Euro Surveill. 2020;25:2001974. https://doi.org/10.2807/1560-7917. ES.2020.25.50.2001974.

11. Davies NG, Barnard RC, Jarvis CI, Russell TW, Semple MG, Jit M, et al. Association of Tiered Restrictions and a Second Lockdown with COVID19 Deaths and Hospital Admissions in England: a Modelling Study. Lancet Infect Dis. 2021:21:482-92. https://doi.org/10.1016/S14733099(20)30984-1

12. Meidan D, Schulmann N, Cohen R, Haber S, Yaniv E, Sarid R, Barzel B. Alternating Quarantine for Sustainable Epidemic Mitigation. Nat Commun. 202 1;12:220. https://doi.org/10.1038/s41467-020-20324-8.

13. Rawson T, Brewer T, Veltcheva D, Huntingford C, Bonsall MB. How and When to End the COVID-19 Lockdown: an Optimization Approach. Front Public Health. 2020;8:262. https://doi.org/10.3389/fpubh.2020.00262.

14. Rawson T, Huntingford C, Bonsall MB. Temporary "Circuit Breaker" Lockdowns Could Effectively Delay a COVID-19 Second Wave Infection Peak to Early Spring. Front Public Health. 2020;8:614945. https://doi. org/10.3389/fpubh.2020.614945.
15. Cheng Q, Liu Z, Cheng G, Huang J. Heterogeneity and Effectiveness Analysis of COVID-19 Prevention and Control in Major Cities in China Through Time-Varying Reproduction Number Estimation. Sci Rep. 2020;10:21953. https://doi.org/10.1038/s41598-020-79063-x.

16. Faranda D, Alberti T. Modeling the Second Wave of COVID-19 Infections in France and Italy via a Stochastic SEIR Model. Chaos. 2020;30:111101. https://doi.org/10.1063/5.0015943.

17. Bosetti P, Kiem CT, Yazdanpanah Y, Fontanet A, Lina B, Colizza V, Cauchemez S. Impact of Mass Testing During an Epidemic Rebound of SARS-CoV-2: a Modelling Study Using the Example of France. Euro Surveill. 2021;26:2001978. https://doi.org/10.2807/1560-7917.ES. 2020.26.1.2001978.

18. Bhadauria AS, Pathak R, Chaudhary M. A SIQ Mathematical Model on COVID-19 Investigating the Lockdown Effect. Infect Dis Model. 2021;6:244-257. https://doi.org/10.1016/j.idm.2020.12.010.

19. Johanna N, Citrawijaya H, Wangge G. Mass Screening vs Lockdown vs Combination of Both to Control COVID-19: a Systematic Review. J Public Health Res. 2020;9:2011. https://doi.org/10.4081/jphr.2020.2011.

Publisher's Note: Springer Nature remains neutral with regard to jurisdictional claims in published maps and institutional affiliations. 